
A C S
$S Y M P O$
OSIU
M
SERIES
499

\title{
Supramolecular Architecture
}

\section{Synthetic Control in Thin Films and Solids}

\author{
Thomas Bein, EDITOR
}

Purdue University

Developed from a symposium sponsored by the Division of Inorganic Chemistry

at the 201st National Meeting of the American Chemical Society,

Atlanta, Georgia,

April 14-19, 1991

American Chemical Society, Washington, DC 1992 


\section{Contents}

Preface

xi

1. Supramolecular Architecture: Tailoring Structure and

Function of Extended Assemblies.

Thomas Bein

TWo-DimENSIONAL ASSEMBLIES: THIN FILMS

2. Designing Ordered Molecular Arrays in Two and Three Dimensions

John P. Folkers, Jonathan A. Zerkowski, Paul E. Laibinis, Christopher T. Seto, and George M. Whitesides

3. Synthesis and Deposition of Electron Donors, Acceptors, and Insulators as Components of Zirconium Diphosphonate Multilayer Films.

H. E. Katz, M. L. Schilling, S. Ungashe, T. M. Putvinski, and C. E. Chidsey

4. Synthesis and Properties of Novel Low-Dimensional

Ruthenium Materials: Self-Assembled Multilayers and Mixed Inorganic-Organic Polymers

DeQuan Li, Sara C. Huckett, Tracey Frankcom,

M. T. Paffett, J. D. Farr, M. E. Hawley, S. Gottesfeld,

J. D. Thompson, Carol J. Burns, and Basil I. Swanson

5. Langmuir-Blodgett Films of Transition-Metal Complexes...........

R. E. Des Enfants II, Teddy A. Martinez, and

M. Keith De Armond

6. Biomimetic Thin-Film Synthesis

Peter C. Rieke, Barbara J. Tarasevich, Susan B. Bentjen,

Glen E. Fryxell, and Allison A. Campbell 
7. Nanoscale Surface-Modification Techniques Using the Scanning Tunneling Microscope.

Bruce Parkinson

\section{LAYERED AND LOW-DIMENSIONAL STRUCTURES}

8. Design and Chemical Reactivity of Low-Dimensional Solids: Some Soft Chemistry Routes to New Solids

Jean Rouxel

9. Iron Oxychloride as a Precursor to Lamellar Iron

Phosphonates by Soft Chemistry

P. Palvadeau, Jean Rouxel, M. Queignec, and B. Bujoli

10. Pillared Layered Materials

Abraham Clearfield and Mark Kuchenmeister

11. Organoclay Assemblies and Their Properties as Triphase Catalysts .

Chi-Li Lin, Ton Lee, and Thomas J. Pinnavaia

12. Thermal Analysis of Porphyrin-Clay Complexes

K. A. Carrado, K. B. Anderson, and P. S. Grutkoski

13. Synthesis and Study of Asymmetrically Layered Zirconium Phosphonates

David A. Burwell and Mark E. Thompson

14. Polyether and Polyimine Derivatives of Layered Zirconium Phosphates as Supramolecules

Abraham Clearfield and C. Yolanda Ortiz-Avila

15. Crystalline Inorganic Hosts as Media for the Synthesis of Conductive Polymers

M. G. Kanatzidis, C.-G. Wu, H. O. Marcy, D. C. DeGroot,

J. L. Schindler, C. R. Kannewurf, M. Benz, and E. LeGoff

16. Intercalation and Polymerization of Aniline in Layered Protonic Conductors

Deborah J. Jones, Raja El Mejjad, and Jacques Rozière

17. Electrocrystallization of Low-Dimensional Molecular Solids 231

Michael D. Ward 
18. Electrodeposition of Nanoscale Artificially Layered Ceramics.... 244 Jay A. Switzer, Richard J. Phillips, and Ryne P. Raffaelle

THREE-DIMENSIONAL FRAMEWORKS AND AMORPHOUS NETWORKS

19. Crystal Engineering of Novel Materials Composed of Infinite Two- and Three-Dimensional Frameworks.

Richard Robson, Brendan F. Abrahams, Stuart R. Batten, Robert W. Gable, Bernard F. Hoskins, and Jianping Liu

20. Zeolite Inclusion Chemistry: Clusters, Quantum Dots, and Polymers

Thomas Bein

21. Three-Dimensional Periodic Packaging: Sodalite, a Model System

G. D. Stucky, V. I. Srdanov, W. T. A. Harrison, T. E. Gier,

N. L. Keder, K. L. Moran, K. Haug, and H. I. Metiu

22. Topotactic Kinetics in Zeolite Nanoreaction Chambers

Geoffrey A. Ozin, Saim Özkar, Heloise O. Pastore, Anthony J. Poë, and Eduardo J. S. Vichi

23. Self-Assembling Electron-Transport Chains in Zeolites: Molecular Bilayer Rectifiers and Photodiodes.

Yeong Il Kim, Richard L. Riley, Edward H. Yonemoto,

Daiting Rong, and Thomas E. Mallouk

24. Synthesis of $\mathrm{NaX}$ Zeolites with Metallophthalocyanines

Kenneth J. Balkus, Jr., C. Douglas Hargis, and

Stanislaw Kowalak

25. Synthesis via Superlattice Reactants: Low-Temperature Access to Metastable Amorphous Intermediates and Crystalline Products

Thomas Novet, Loreli Fister, Christopher A. Grant, and

David C. Johnson

26. Solid-State Metathesis Routes to Layered Transition-Metal Dichalcogenides and Refractory Materials

John B. Wiley, Philippe R. Bonneau, Randolph E. Treece, Robert F. Jarvis, Jr., Edward G. Gillan, Lin Rao, and Richard B. Kaner 
27. Encapsulation of Organic Molecules and Enzymes in Sol-Gel Glasses: A Review of Novel Photoactive, Optical, Sensing, and Bioactive Materials.

David Avnir, Sergei Braun, and Michael Ottolenghi

28. Sol-Gel Preparation of Optically Clear Supported Thin-Film Glasses Embodying Laser Dyes: Novel Fast Method. 405 Y. Haruvy, A. Heller, and S. E. Webber

\section{INDEXES}

Author Index

Affiliation Index 428

Subject Index 428 


\title{
Chapter 20
}

\section{Zeolite Inclusion Chemistry}

\author{
Clusters, Quantum Dots, and Polymers
}

\author{
Thomas Bein
}

Department of Chemistry, Purdue University, West Lafayette, IN 47907

\begin{abstract}
An overview on zeolite structures and properties is given, followed by a discussion of various strategies for the intrazeolite encapsulation of metal clusters and organometallics, quantum size semiconductor clusters, and polymer filaments. Several examples are described in more detail. Palladium clusters of low nuclearity have been prepared in the cavities of $\mathrm{X}$ zeolites via ion exchange with $\mathrm{Pd}\left(\mathrm{NH}_{3}\right)_{4} \mathrm{Cl}_{2}$, oxidative dehydration, and subsequent reduction of the dry $\mathrm{Pd}(\mathrm{II}) z e o l i t e s$ with hydrogen at $295 \mathrm{~K}$. EXAFS analysis of Pd K-edge data shows that intrazeolite $\mathrm{Pd}_{2-4}$ clusters are formed by partial occupation of SI' and SII' positions of the sodalite subunits of the zeolite. Ensembles of $\mathrm{CdSe}$ have been synthesized within the cage system of zeolite $\mathrm{Y}$ via ion exchange with $\mathrm{Cd}(\mathrm{II})$ and subsequent treatment with $\mathrm{H}_{2} \mathrm{Se}$. $\mathrm{Se}, \mathrm{O}$ bridged cadmium dimers and $\mathrm{Cd}_{4} \mathrm{O}_{4}$ cubes are formed in the sodalite unit. The anchoring chemistry of $\mathrm{Me}_{3} \mathrm{SnMn}(\mathrm{CO})_{5}$ in acid forms of zeolite Y was studied with X-ray absorption spectroscopy (Sn, Mn edge EXAFS) and in-situ FTIR/TPD-MS techniques. The compound attaches to the zeolite framework at the oxygen rings of the supercage. The attachment of the molecule occurs through the Sn moiety by loss of $\mathrm{CH}_{4}$ gas while the $\mathrm{Sn}-\mathrm{Mn}$ bond and the $\mathrm{CO}$ ligand sphere are still intact. Different degrees of substitution of the methyl groups by the acidic oxygen framework are observed. Intrazeolite polyacrylonitrile (PAN) was formed from preadsorbed acrylonitrile in zeolite $\mathrm{Y}$ and mordenite on reaction with radical initiators. Chain length analysis with gel permeation chromatography revealed a peak molecular weight of 19,000 for PAN in NaY, and about 1,000 for the polymer in mordenite. When intrazeolite PAN is pyrolyzed under nitrogen, black encapsulated material results that has lost the nitrile groups and hydrogen. After recovery from the zeolite hosts, the pyrolyzed polyacrylonitrile shows electronic DC conductivity at the order of $10^{-5} \mathrm{Scm}^{-1}$.
\end{abstract}

\section{Zeolites Inclusion Chemistry: Structure and Properties of the Host}

Few classes of inorganic solids have gained as much importance for host/guest chemistry as the microporous aluminosilicates called zeolites. ${ }^{1,2,3}$ While many layered materials are known, including aluminosilicate clays, group 4 phosphates, graphite, 
and metal chalcogenides, zeolites are the archetypical three-dimensional "molecular sieves". One major difference between these materials is that structural integrity of the zeolites upon encapsulation or intercalation of guest molecules is maintained, while the layered structures change the interlayer spacing and interlayer orientation when intercalation takes place. There are several other groups of crystalline microporous structures of growing importance, for example molybdenum phosphates, ${ }^{4}$ or metal sulfides, ${ }^{5}$ which are not subject of this discussion.

Zeolites are open framework oxide structures (classically aluminosilicates with hydrophilic surfaces) with pore sizes between 0.3 and $1.2 \mathrm{~nm}$ and exchangeable cations. The fundamental building blocks of the classical zeolite structure are the $\mathrm{SiO}_{4}$ and $\mathrm{AlO}_{4}$ tetrahedra that are conceptually viewed as joining up in "secondary building units" such as single six-rings (S6R, which are in fact twelve-rings consisting of six metals and six alternating oxygens arranged much like a crown ether), double-six-rings (D6R) and complex 5-1 structures. Other important structural units are the "sodalite cage" (a truncated octahedron) and the "supercage" (a unit with $12.5 \AA$ internal diameter). These units are then joined to form open pore structures with channels based on rings containing 6 to 20 (in a gallophosphate) metal and oxygen atoms. Not only channels but also cage structures can be formed. There are now more than seventy different structure types known and new ones continue to emerge. Zeolites have remarkable temperature stability; survival of structures at $1000 \mathrm{~K}$ is not uncommon. The presence of $\mathrm{Al}$ atoms in the silica framework results in one negative charge per $\mathrm{Al}$ atom such that cations are required to balance the charge. The zeolitic pores constitute a significant fraction of the crystal volume (up to about $50 \%$ ) and are usually filled with water. In hydrated zeolites, the cations have a high mobility giving rise to ion exchange capability, and the water molecules can be removed at elevated temperature. A general formula for zeolite-type materials based on 4-connected networks is the following6:

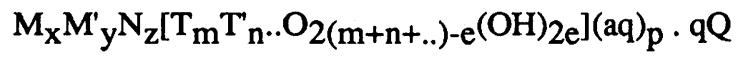

with tetrahedral T-atoms $\mathrm{Be}, \mathrm{B}, \mathrm{Al}, \mathrm{Ga}, \underline{\mathrm{Si}}, \mathrm{Ge}, \mathrm{P}$, transition metals, and $\mathrm{M}, \mathrm{M}^{\prime}$ exchangeable and nonexchangeable cations, $\mathrm{N}$ nonmetallic cations (normally removable on heating), (aq) chemically bonded water and $Q$ sorbate molecules which need not be water. The essential part in the square brackets represents the 4-connected framework which is usually anionic. A simpler formula used for many zeolites is:

$$
\left(\mathrm{M}^{\mathrm{n}+}\right)_{\mathrm{x} / \mathrm{n}}\left[\left(\mathrm{AlO}_{2}\right)_{\mathbf{x}}\left(\mathrm{SiO}_{2}\right)_{\mathrm{y}}\right] . \mathrm{zH}_{2} \mathrm{O}
$$

Structures of representative zeolites. ${ }^{7}$ The following Table 1 presents a brief description of important zeolite structure types. Structural building blocks and cage topologies of those zeolites are shown in Figure 1. Zeolite A (LTA) consists of cubooctahedra (sodalite cages) linked together through double four-rings (D4R) to form a central cage (alpha-cage), accessible through six S8R with a free diameter of $4.1 \AA$.

Zeolite $\mathrm{Y}$ is isostructural with zeolite $\mathrm{X}$ (FAU). It differs from the latter in its higher Si/Al ratio which reduces the number of cations present in the framework. Zeolite X contains typically about 88 cations per unit cell, while Y contains about 56. The framework consists of sodalite cages, connected through four D6R that enclose a supercage with $12.5 \AA$ internal diameter. The supercages are accessible through four S12R windows with a free aperture of $7.4 \AA$. Relevant cation locations are the center of the hexagonal prism (site SI) and in the six-membered rings connecting into the sodalite (SI'; SII') and into the supercage (SII). The ions are often slightly displaced from the center plane of the rings. 
In mordenite (MOR), complex 5-1 units form two major intersecting channels, one defined by windows with oxygen 12 -rings $(6.5 \AA \times 7.0 \AA)$ and one defined by windows with oxygen 8 -rings. Mordenite is thermally very stable due to the large number of energetically favored five-membered rings in the framework.

Silicalite (MFI), $\mathrm{Si}_{96} \mathrm{O}_{192}$, belongs to the pentasil family of which the isostructural ZSM-5 is the most prominent. It has two intersecting pore systems, one consisting of zig-zag channels of near-circular cross section $(5.3 \times 5.6 \AA)$ and another of straight channels of elliptical shape $(5.1 \times 5.5 \AA)$ perpendicular to the first. All the intersections in silicalite are of the same size. The heat of adsorption and the room temperature uptake of water is small compared to the Al-containing zeolites.

Table 1. Representative Zeolite Structure Types.

Name

LTA, Linde A

FAU, Faujasite

RHO, Rho

MOR, Mordenite

MFI, ZSM-5

AFI, AIPO-5
Unit Cell/Composition

$$
\begin{aligned}
& \mathrm{Na}_{12}\left[\left(\mathrm{AlO}_{2}\right)_{12}\left(\mathrm{SiO}_{2}\right)_{12}\right] 27 \mathrm{H}_{2} \mathrm{O} \\
& \mathrm{Na}_{58}\left[\left(\mathrm{AlO}_{28}\right)_{58}\left(\mathrm{SiO}_{2}\right)_{134}\right] 240 \mathrm{H}_{2} \mathrm{O} \\
& \mathrm{Na}_{12}\left[\left(\mathrm{AlO}_{2}\right)_{12}\left(\mathrm{SiO}_{2}\right)_{36}\right] 44 \mathrm{H}_{2} \mathrm{O} \\
& \mathrm{Na}_{8}\left[\left(\mathrm{AlO}_{2}\right)_{8}\left(\mathrm{SiO}_{2}\right)_{40}\right] 24 \mathrm{H}_{2} \mathrm{O} \\
& \mathrm{Na}_{\mathrm{n}}\left[\left(\mathrm{AlO}_{2}\right)_{\mathrm{n}}\left(\mathrm{SiO}_{2}\right)_{96-\mathrm{n}}\right] 16 \mathrm{H}_{2} \mathrm{O} \\
& \mathrm{AlPO}_{4}
\end{aligned}
$$

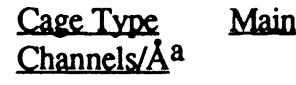

a, B

B, 26-hedron(II)

a, D8R

complex 5-1

complex 5-1

$12 R$
$4.1 * * *$

$7.4 * * *$

$3.9 \times 5.1 * * *$

$6.5 \times 7.0^{*}<->$

$2.6 \times 5.7^{*}$

$\{5.3 \times 5.6<->$

$5.1 \times 5.5\}$ ***

7.3 *

a The number of stars $(*)$ at the channel description indicates the dimensionality of channel connections. The cage types are depicted in Figure 1.

Zeolite synthesis. ${ }^{8}$ A typical synthesis involves an aluminosilicate gel prepared from silicate and aluminate sources, hydroxide, and water, which is crystallized under hydrothermal conditions. Many zeolite preparations also contain organic cations such as tetramethyl ammonium hydroxide. ${ }^{9}$ The organic cations are thought to be structuredirecting templates, at least to a certain degree, because their presence changes the resulting zeolite phase and because they are often incorporated in the pores during synthesis. For example, tetrapropylammonium (TPA) ions are sited at the intersections of four channels in ZSM-5 with each of the four propyl groups directed along individual channels. ${ }^{10}$ The $\mathrm{SiO}_{2} / \mathrm{Al}_{2} \mathrm{O}_{3}$ ratio in these gels influences the final framework composition of the product, and usually all the aluminium available is incorporated into the final zeolite composition. The $\mathrm{H}_{2} \mathrm{O} / \mathrm{SiO}_{2}$ and $\mathrm{OH}^{-} / \mathrm{SiO}_{2}$ ratios strongly influence the nature of the polymeric species present, and the rate of conversion of these species to three-dimensional zeolite frameworks.

Adsorption and acidity in zeolites. Intrazeolite water can be removed from the pores by heating and/or evacuating, resulting in a large, accessible intracrystalline surface area. Access of other species is limited to molecules having effective diameters small enough to enter the pores. However, the zeolite framework has a certain flexibility such that the pore size expands at elevated temperature. A classical example is the exclusion of nitrogen in $\mathrm{NaA}$ zeolite at cryogenic temperature $(77 \mathrm{~K})$, while at $180 \mathrm{~K}$, the windows have expanded enough to adsorb 5 molecules of nitrogen in each cage. Other important factors influencing adsorption are polarizability of the adsorbate, wettability of the zeolite surface, and electric field gradients near cations. Zeolites 
A
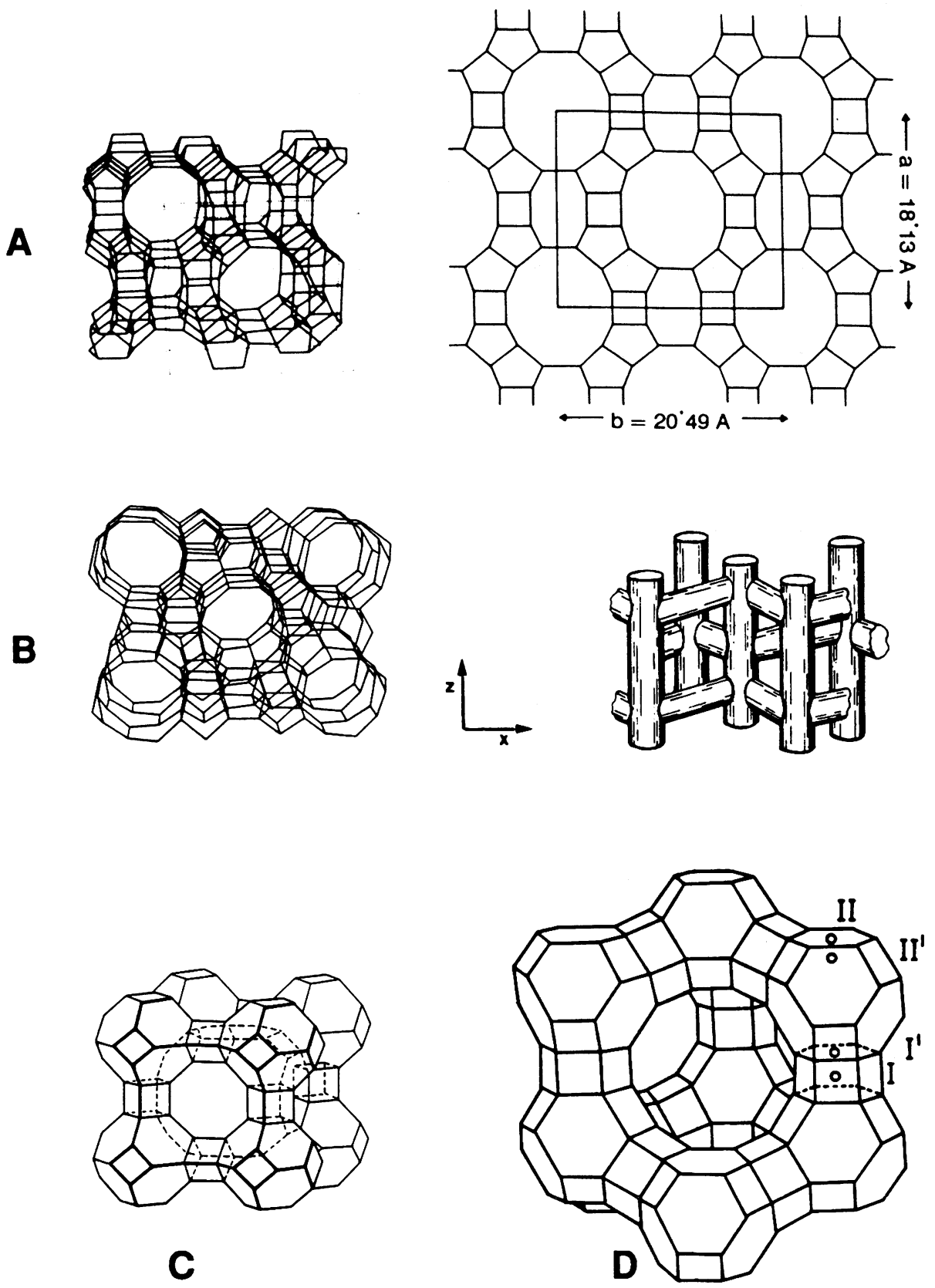

Figure 1. The structures of zeolites. A, Mordenite, B, Silicalite, C, zeolite A, and D, Faujasite. 
exhibit type I adsorption isotherms, where the initial rise at low partial pressure is associated with micropore filling.

Moderate acid will replace the original cations by hydronium ions; ${ }^{11}$ the material can be heated to form hydrogen zeolites:

$\mathrm{H}_{3} \mathrm{O}^{+} \mathrm{ZO}^{-} \rightarrow \mathrm{H}^{+} \mathrm{ZO}^{-}+\mathrm{H}_{2} \mathrm{O}$

Bronsted acidity can also be introduced by hydrolysis of hydrated transition metal ions, and ammonium exchange with subsequent removal of ammonia under heating. ${ }^{12}$

The variety of zeolites and zeolite-related materials has grown enormously in recent years with the incorporation of transition metals into the framework, 13 and the discovery of metal aluminophosphate sieves. ${ }^{14}$ Structural analogs to the zeolites as well as new structures with $\mathrm{AlPO}_{4}$ elemental composition ${ }^{15}$ include one example with a pore size greater than that of zeolite Y (VPI-5, pore size $\sim 12 \AA) .16$ Silicon has been incorporated into many of the $\mathrm{AlPO}_{4}$ structures resulting in negatively charged frameworks. ${ }^{17}$ New developments include the titanosilicates ${ }^{18}$ containing octahedral Ti and the gallophosphate "cloverite" with impressive clover-like channels formed by 20 membered rings. ${ }^{19}$

\section{Zeolites Inclusion Chemistry: Encapsulation Strategies}

The crystalline microporosity and well-defined internal surfaces of zeolites, in addition to their great chemical variety, make these materials very attractive hosts for many areas of inclusion chemistry. ${ }^{20} \mathrm{~A}$ brief overview of encapsulation strategies follows.

The two most obvious and common ways to incorporate matter into zeolite pores are (i) by adsorption and diffusion from gas or liquid phase, and (ii) by ion exchange. A third, usually more difficult approach involves incorporation of species during hydrothermal synthesis. The zeolite pores can be viewed as nanometer size reaction chambers that accommodate numerous organic and inorganic molecules with enough space for chemical conversions. It follows that there is a vast potential for ingenious chemistry in these hosts.

Supported metal clusters are important for catalytic applications and have therefore attracted attention for many years. Noble metals have been introduced into zeolites by ion exchange of complex cations such as $\mathrm{Pd}\left(\mathrm{NH}_{3}\right)_{4}{ }^{2+}$. Degassing in oxygen eliminates premature autoreduction, 21 and subsequent hydrogen reduction forms very small metal clusters stabilized by the zeolite structure. (see example of Pd zeolites below). Other, more powerful reducing agents including $\mathrm{H}$-atoms and sodium vapor have been used for metals such as $\mathrm{Ni}$ or $\mathrm{Fe}$. Often a particle size distribution with additional external phase is obtained.

Metals can also be introduced by adsorption of the elemental vapor or melt, for instance in the case of mercury or alkali metals. Adsorption of molecular "precursors" such as carbonyls of iron, cobalt, nickel and molybdenum, and subsequent thermal or photochemical decomposition has become an important approach for metals that are difficult to reduce. Other ligands such as alkyls or acetylacetonates have also been used for this purpose. In all these cases, thermal decomposition carries the risk of excessive mobility of the precursors or intermediates such that agglomeration and particle formation at the external surface of the zeolite crystals can occur. Barrer has described the synthesis of salt-bearing zeolites including the famous dry synthesis of ultramarin in 1828 , which is sodalite containing intercalated Na-polysulphides. ${ }^{22}$ Adsorption of numerous non-ionic and salt species into zeolites was also described, either as such or as precursors for oxides, hydroxides, or metals. 
Examples in four different areas of zeolite inclusion chemistry will be discussed in the following. Noble metal and semiconductor clusters, organometallics, and intrazeolite polymer filaments are objects of new and continued research activity.

Palladium Ensembles in Zeolites. Small metal particles or clusters have attracted great interest during the last decade. The optical, electronic and catalytic characteristics of clusters are expected to change from 'bulk' properties to 'molecular' properties within a certain size-range. ${ }^{23.24}$ This change is represented by the transition of the electronic band structure of a crystal to the molecular orbital levels of species few atoms in size. Since the cluster size determines the relative population of coordination sites 25 and possibly its molecular symmetry, it is thought to be responsible for modified selectivities in a number of catalytic reactions. ${ }^{26}$ Controlled synthesis of stable clusters with defined size is of particular interest, because this would potentially allow to finetune the properties of electronic materials and catalyst systems.

The particle size of $\mathrm{Pd}$ and $\mathrm{Pt}$ phases encapsulated in zeolite hosts can be controlled by chosing appropriate reduction conditions for the ion exchanged, dehydrated precursor form. 27,28.29 Based on x-ray diffraction studies, a bidisperse distribution of Pd particles appears to be typical: In addition to particles 10-20 $\AA$ in size, a second $\mathrm{Pd}$ phase was assigned to $\mathrm{Pd}$ atoms in the cage systems. ${ }^{30,31}$ In the following we describe the synthesis and characterization of Pd ensembles, consisting of 2 to 4 correlated atoms, which are stabilized at room temperature in an open, chemically accessible zeolite matrix. ${ }^{32}$ Characterization of the clusters was done by means of $x$-ray absorption spectroscopy (EXAFS). ${ }^{33,34}$

$\mathrm{Pd}\left(\mathrm{NH}_{3}\right)_{4}{ }^{2+}$ was ion exchanged into zeolite $\mathrm{NaX}$. Fourier transformed EXAFS data of Pd-X zeolite samples after different treatments are shown in Figure 2: after oxygen pretreatment at $625 \mathrm{~K}$ (PdXO, Figure 2.A); and after subsequent $\mathrm{H}_{2}$ exposure at room temperature (PdX, Figure 2.B). In sample $\mathrm{PdXO}$, the coordination of $\mathrm{Pd}^{2+}$ to oxygen with a Pd-O distance of $2.07 \AA$ ( $1.5 \AA$ uncorrected for phase shifts; fit results give the true distances) is detected as the main peak. This corresponds exactly to results from $x$-ray diffraction studies of similar palladium exchanged zeolites. The coordination of $\mathrm{Pd}$ to the zeolite is indicated in the EXAFS spectrum by the concomitant appearence of a peak at about $3.0 \AA$ (uncorrected), typical for $\mathrm{Si} / \mathrm{Al}$ scatterer of the zeolite framework.

If the sample $\mathrm{PdXO}$ is exposed to hydrogen at $295 \mathrm{~K}(\mathrm{PdX})$, drastic changes are visible in the corresponding EXAFS data. The data do not show any sign of remaining cationic Pd-zeolite-oxygen coordination between 1 to $2 \AA$, the range of the $\mathrm{Pd}-\mathrm{O}$ contribution in sample PdXO. Instead, a very small, well-resolved contribution from Pd-Pd scattering is present. No outer palladium shells are visible, indicating an extremely small cluster size.

Analysis of the corresponding EXAFS data shows that under carefully chosen conditions it is possible to achieve a total reduction of zeolite-supported palladium cations to metal clusters of molecular size at room temperature. This is concluded from the fact that no remaining ionic Pd-oxygen coordination at the original distance of 2.07 $\AA$ (sample PdXO) is detected after reduction in sample PdX. A new, disordered Pd-O coordination at $2.76 \AA$ in sample PdX is resulting from a weak interaction between the reduced metal atoms and the support which gives rise to an increased static disorder. Similar long metal-oxygen bond distances have been reported for a palladium phase in $\mathrm{Y}$ zeolites $\left(\mathrm{Pd}-\mathrm{O}=2.74 \AA \text { after } \mathrm{H}_{2} \text { reduction at } 420 \mathrm{~K}\right)^{22}$, and for silver clusters in zeolite $\mathrm{Y}\left(\mathrm{Ag}-\mathrm{O}=2.67\right.$ and $2.79 \AA$ after $\mathrm{H}_{2}$ reduction at $\left.348 \mathrm{~K}\right)$. The average coordination number of Pd-Pd in the zeolite is 1.5 . This could point to the formation of dimeric and trimeric clusters. On average each Pd atom is surrounded by 3 oxygens and six $\mathrm{Si} / \mathrm{Al}$ atoms. 

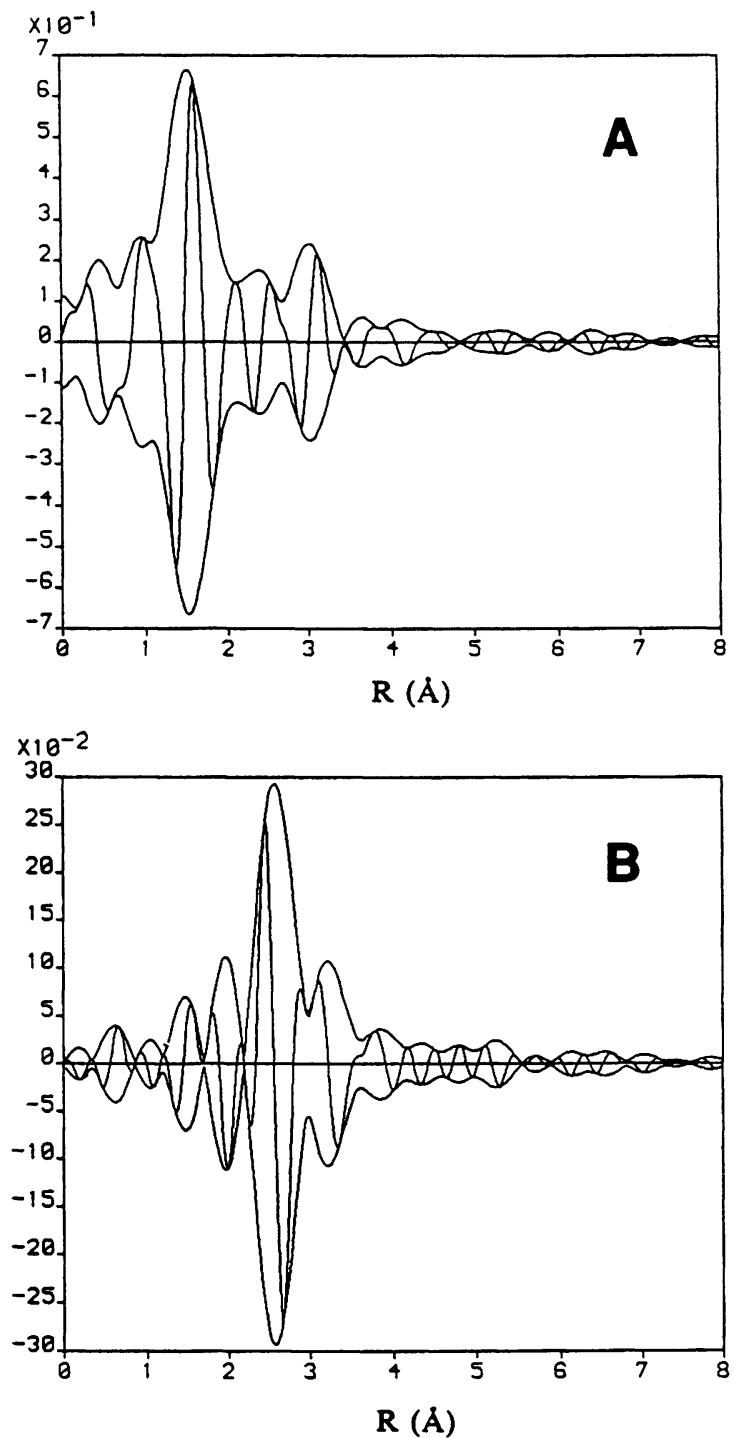

Figure 2. Fourier transformed EXAFS data of A, Sample PdXO; B, Sample PdX. 
A model arrangement of four palladium atoms occupying the sodalite unit as shown in Figure 3 corresponds to an average $P d-P d$ coordination of $N=1.5$. Each palladium atom is located in front of one hexagonal window in dislocated SI or SI' positions within the sodalite unit (SI'* and $\left.\mathrm{SII}^{\prime *}\right)$. The $\mathrm{SI}^{\prime}$ sodalite position is surrounded by three nearest SII' positions and vice versa. Our proposed model of $\mathrm{Pd}_{2}$ to $\mathrm{Pd}_{4}$ molecular clusters is comparable to the structure of silver clusters in sodalite units, where the participating Ag atoms were located in SI'* and SII'* positions. Furthermore, $x$-ray diffraction studies of $\mathrm{Ca}$ (II)-exchanged and dehydrated zeolite $\mathrm{Y}$ and of $\mathrm{Cd}$ (II)-exchanged zeolites $\mathrm{X}$ were interpreted with very similar arrangements in $\mathrm{SI}^{*}$ positions, which are stabilized by $\mathrm{OH}$ or $\mathrm{H}_{2} \mathrm{O}$ in SII' positions. ${ }^{35.36}$

The intrazeolite stabilization of the unusually small Pd clusters is possible through the interplay of two types of interaction: (1) The zeolite sodalite cage offers a stabilizing oxygen-coordination sphere for the reduced Pd atoms. (2) In addition, the different sets of SI'* and SII'* cage positions provide templates for the arrangement of palladium ensembles with sufficient Pd-Pd bonding overlap. These well-defined 'molecular clusters' with low nuclearity stabilized at ambient temperature in an open pore structure are attractive model systems to study changes in electronic, optical and vibrational characteristics, and to explore their catalytic properties under reaction conditions.

Quantum Size Cadmium Selenide Clusters in Zeolite Y. The preparation of well-defined semiconducting clusters with homogeneous morphology and size distribution is a prerequisite for understanding the physical origin of quantum size effects and exciton formation. 37,38,39 Classical preparation methods for these clusters include wet colloidal techniques, ${ }^{40,41,42,43,44}$ and growth in dielectric glassy matrices, ${ }^{45}$

or in polymers. ${ }^{46}$ However, particle sizes obtained with these techniques are usually non-uniform and agglomeration of individual particles often occurs. 47 Zeolites are excellent hosts for nanometer size semiconductor clusters, ${ }^{48}$ as demonstrated with $\mathrm{Se}$ species and CdS clusters. ${ }^{49,50}$ A structural study of related cadmium selenide clusters stabilized in zeolite $\mathrm{Y}$ is discussed below. ${ }^{51}$ Colloidal cadmium selenide is of interest for photosensitized electron-transfer reactions utilized for solar energy conversion and photocatalysis. $52,53,54$

Synthesis of intrazeolite CdSe was achieved by ion exchange with Cd(II), subsequent heating in oxygen to $673 \mathrm{~K}$, and exposure to $\mathrm{H}_{2} \mathrm{Se}$ gas at $298 \mathrm{~K}$. Cluster size and geometrical arrangements could be determined by comprehensive analysis of Cd- and Se-edge EXAFS data as well as synchrotron $\mathrm{x}$-ray powder diffraction and model calculations.

A comparison between EXAFS data of the cadmium-exchanged zeolite CdY and the samples treated with hydrogen selenide gas shows that major changes occur. From EXAFS data analysis and $\mathrm{x}$-ray diffraction data of $\mathrm{Cd}(\mathrm{II})$ zeolite $\mathrm{Y}$ it was found that four $\mathrm{Cd}^{2+}$ ions occupy $\mathrm{SI}^{\prime}$ cation positions in the sodalite cages, and that they are bridged by oxygen in adjacent SII' six-ring sites, thus forming small $\mathrm{Cd}_{4} \mathrm{O}_{4}$ cubes. On exposure to $\mathrm{H}_{2} \mathrm{Se}$ it is expected that the selenium reacts with cadmium and the sample is expected to differ from the $\mathrm{Cd}(\mathrm{II})$ zeolite in its overall appearance primarily by an additional selenium shell. If the Fourier transforms of both samples are compared, a new peak at about $2.3 \AA$ (uncorrected) in the CdSe-Y sample appears due to the selenide in this system. This assignment is further justified by the striking similarity in phase function and location in R-space to that of a reference sample of bulk CdSe.

$\mathrm{X}$-ray powder data show that the $\mathrm{Cd}^{2+}$ in this sample is located primarily at $\mathrm{SI}^{\prime}$. This site, within the sodalite unit, is preferred by multivalent cations because some of the high charge density can be compensated by hydroxyl anions at SII', also in the sodalite unit. The cadmium at SI' has a pseudo octahedral coordination resulting from trigonal coordination to framework oxygens of the six-ring (which is part of the double 


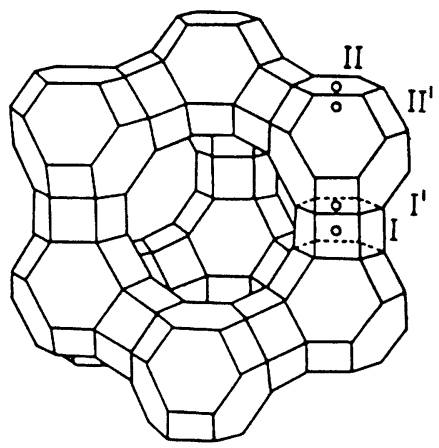

A
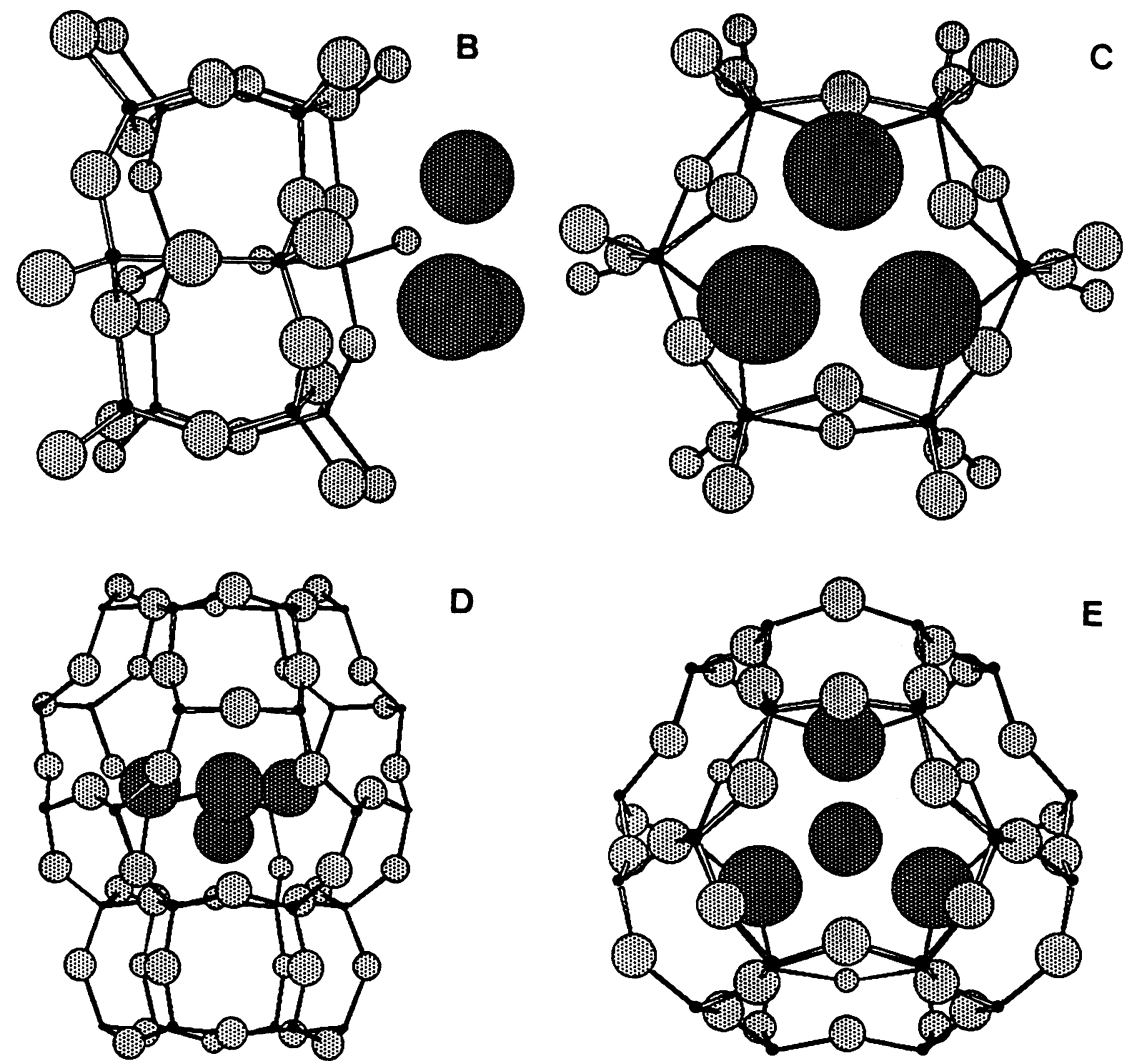

D

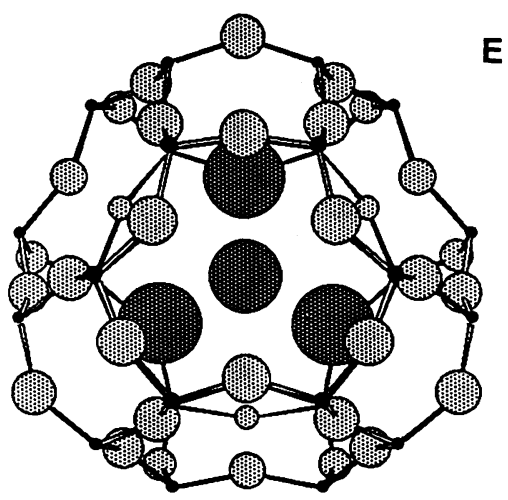

Figure 3. Geometric arrangements of palladium ensembles in a faujasite subunit. A: display of a partial faujasite unit cell with cation positions SI, SI', SII and SII. B,C: geometric arrangements of a palladium trimer located in front of a double six-ring (side and top view; Pd atoms dark-shaded). D,E: four Pd atoms located in adjacent ST and SIT windows in a sodalite cage. Radii of atoms are sized as follows: $\mathrm{Si}^{4+}=0.42 \AA, \mathrm{O}^{2-}=$ $1.32 \AA, \mathrm{Pd}(0)=1.37 \AA$. $\mathrm{Si}^{4+}$ and $\mathrm{O}^{2-}$ atoms are shown with $30 \%$ of their ionic radii, $\mathrm{Pd}(0)$ with $60 \%$ of its metallic radius.

From ref. 32. Copyright 1989 American Chemical Society. 
six-ring interconnects of the zeolite $Y$ structure) with a bond length of $\mathrm{Cd}(1)-\mathrm{O}(3)=$ $2.41 \AA$, and the three SII' atoms, $\mathrm{Cd}(1)-\mathrm{O}(5)=2.42 \AA . \mathrm{O}(5)$ represents a site jointly occupied by $\mathrm{Se}$ and oxygen and hence the $\mathrm{Cd}(1)-\mathrm{O}(5)$ bond length is a weighted average of Cd-O (EXAFS data: $2.26 \AA$ ) and Cd-Se (EXAFS data: $2.60 \AA$ ).

In the CdSe-Y sample, the major fraction is composed of cadmium cations in adjacent SI' positions bridged on average by two extra-framework oxygen in SII' sites and one additional selenium ion in SII sites. The second phase consists of Cd ions, present in the twelve-ring windows of the large cavities (SIII) coordinated to extra framework oxygen and one selenium.

The EXAFS-derived coordination number for $\mathrm{Cd}-\mathrm{O}(5)$ at $2.26 \AA$ is about half of that expected for a complete cube arrangement (expected for $70 \% \mathrm{Cd}$ located in sodalite cage: $N=3 \times 0.7=2.1$; found: $N=1.4$ ). In addition, the small $\mathrm{Cd}-\mathrm{Cd}$ interaction $(\mathrm{N}=0.4)$ is not sufficient to account for a complete cube arrangement According to the XRD results, the cadmium cations are located in SI' and the $\mathrm{O}^{2-}$ ions in SII' positions. This indicates the formation of oxygen-bridged dimers $\mathrm{Cd}_{2} \mathrm{O}_{2}$. Based on the form factor for oxygen, the occupancy per unit cell was calculated to be 28.9. Since $\mathrm{Cd}_{2} \mathrm{O}_{2}$ dimers would account for only 11.4 oxygens, the remainder is assigned to selenium ions ( 0.4 Se per sodalite cadmium), detected by EXAFS with a bond distance $\mathrm{Cd}-\mathrm{Se}$ of $2.60 \AA$. Thus, on average the sodalite units contain two cadmium ions occupying SI' positions, bridged by two oxygen in SII'. An additional selenium atom in SII' is bound to one cadmium atom (see Figure 4). This arrangement can be considered as a modified fragment of the $\mathrm{Cd}_{4} \mathrm{O}_{4}$ cube found in $\mathrm{CdY}$ zeolite.

The formation of $\mathrm{Cd}-\mathrm{Se}$ ensembles in sodalite subunits must involve diffusion of $\mathrm{H}_{2} \mathrm{Se}$ from the supercage through zeolite six-ring windows with a typical pore opening of $2.6 \AA$. The diameter of $\mathrm{H}_{2} \mathrm{Se}(2.34 \AA)$ clearly allows the diffusion to take place. The intrazeolite $\mathrm{Cd}-\mathrm{Se}$ bond distance derived from this study is close to that of bulk CdSe and indicates some covalent character of these species. It is likely that HSefragments replace the original (O5) species in the precursor $\mathrm{Cd}_{4}(\mathrm{O})_{4}$ cube arrangement, forming $\mathrm{Cd}_{2} \mathrm{O}_{2} \mathrm{Se}$ fragments occupying the sodalite units. Additional $\mathrm{CdO}_{2} \mathrm{Se}$ fragments at SIII positions are also detected. Non-coordinated helical selenium chains and a small fraction of $\mathrm{CdSe}$ are formed primarily in samples with a higher $\mathrm{Se} / \mathrm{Cd}$ ratio.

Reactivity of Trimethyltin Manganesepentacarbonyl in Zeolite Cavities. The immobilization of organometallic catalysts on heterogeneous supports has attracted growing attention, $55,56,57$ because the high selectivity of many molecular catalysts ${ }^{58}$ could be combined with the facile product separation and catalyst recovery inherent to heterogeneous systems. Zeolite hosts might offer additional features such as diffusional or transition state selectivity. Different strategies for the deposition of catalytically active organometallics into zeolites include physisorption of neutral metal carbonyls with only weak framework interactions, 59,60,61,62,63 diffusional blocking ("ship in the bottle" concept) of phthalocyanine (Pc) and other chelate complexes, $64,65,66$ and ligation at transition metal cations. Intrazeolite $\mathrm{Ru}, 67 \mathrm{Ir},{ }^{68}$ and particularly Rh carbonyl complex cations have been studied in great detail.69,70,71 Migration of intrazeolite Rh-carbonyl species and eventual formation of extrazeolite $\mathrm{Rh}(0)$ particles appears to occur under experimental conditions used for catalytic hydroformylation reactions ${ }^{72}$.

Higher stability of the intrazeolite species should be expected from surfaceattached complexes that utilize the bridging zeolite hydroxyls for anchoring reactions, such as the reaction of $\mathrm{Rh}(\text { allyl })_{3}$ with partially proton-exchanged $\mathrm{X}$ and $\mathrm{Y}$ type zeolite. ${ }^{73,74,75,76}$

Immobilization concepts for organometallic fragments in microporous solids are being developed in this laboratory. If two metal centers are present as in 
A

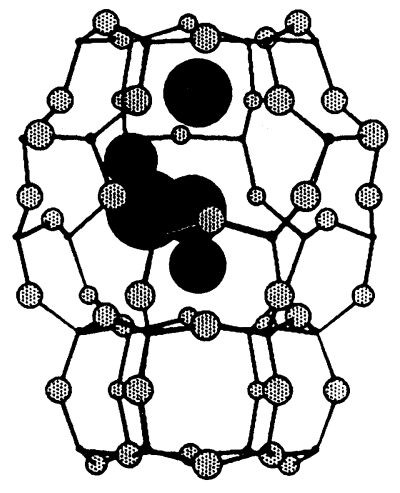

C

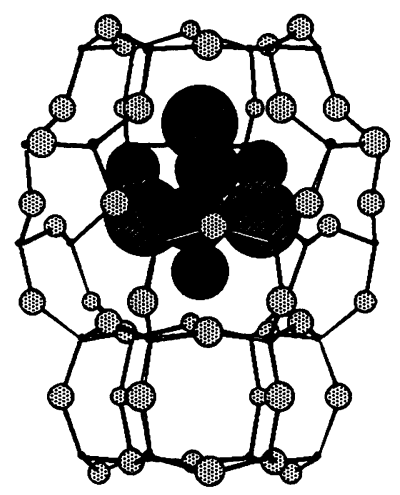

B

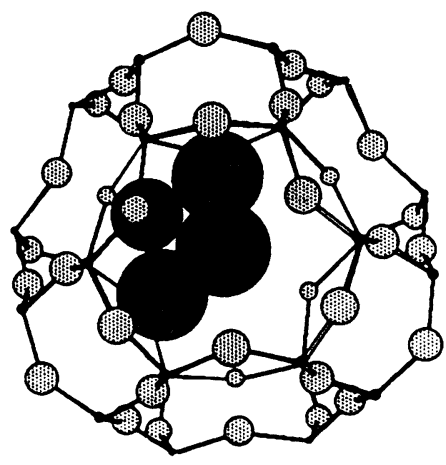

D

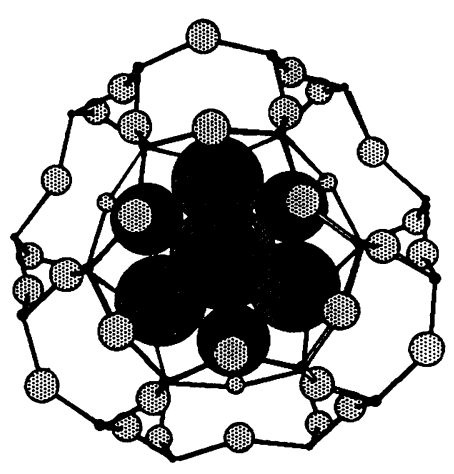

Figure 4. Geometric arrangements of cadmium selenide species in a sodalite subunit of the zeolite framework, viewed from the side and from top. Framework oxygens: light shaded, extra framework oxygens: dark striped, Cd cations black, Se atom light dotted.

Radii $\mathrm{R}=1.32 \AA$ for $\mathrm{O}^{2-}, \mathrm{R}=0.97$ for $\mathrm{Cd}^{2+}, \mathrm{R}=1.17$ for covalent Se. A, B: $\mathrm{Cd}\left(\mathrm{O}_{2}\right) \mathrm{CdSe}$ bridged fragment.

$\mathrm{C}, \mathrm{D}: \mathrm{Cd}_{4} \mathrm{O}_{4}$ cube. One sodalite unit incorporating the $\mathrm{Cd}$ moieties and one of the four interconnecting double six rings of the faujasite framework are presented. All framework atoms are sized $25 \%$ of their radii. For clarity, the cube ensembles are shown with $75 \%$ of the radii. From ref. 51. Copyright 1989 American Chemical Society. 
heterobimetallic complexes, the complex can be 'anchored' to the support via one appropriately chosen, oxophilic metal, whereas the catalytic reaction may proceed at the second metal center. We could recently demonstrate the new bimetallic approach by utilizing the intrazeolite attachment chemistry of Ge-transition metal complexes. ${ }^{77}$ Framework attachment of $\mathrm{Cl}_{2}$ (THF) GeMo(CO) 5 and $\mathrm{Cl}_{2}$ (THF) $\mathrm{GeW}(\mathrm{CO})_{5}$ was possible in both the $\mathrm{Na}$ form of zeolite $\mathrm{Y}$ and in the proton-exchanged form. Both compounds react with the acidic zeolite at elevated temperatures under removal of chloride ligands.

As a recent example, we discuss the surface chemistry and stability of $\mathrm{Me}_{3} \mathrm{SnMn}(\mathrm{CO})_{5}$ in similar zeolite supports. ${ }^{78}$ The precursor is expected to react with the internal surface hydroxyl groups of the zeolites by loss of methane gas whereas the $\mathrm{Sn}-\mathrm{Mn}$ bond and the coordination sphere of Mn should remain intact. EXAFS and in situ FTIR data were used to characterize these systems.

EXAFS: Mn-absorption edge. After adsorption of 0.5 complexes $\mathrm{Me} 3 \mathrm{SnMn}(\mathrm{CO})_{5}$ per supercage from hexane at room temperature into acidic $\mathrm{Y}$ zeolite, a full carbonyl coordination shell remained at the $\mathrm{Mn}$ atom: 5.2 carbon atoms at $1.87 \AA$ and 6.0 oxygen atoms ( $\mathrm{Sn}$ backscattering included) at $2.98 \AA$. At $373 \mathrm{~K}$, the carbonyl coordination remains stable with 4.9 carbon atoms and 6.4 oxygen atoms ( $\mathrm{Sn}$ modulation included) at 1.84 and $2.97 \AA$, respectively. At $423 \mathrm{~K}$, dramatic changes are observed. The carbon and oxygen shells of the $C O$ ligands have disappeared. The EXAFS data indicate the formation of small $\mathrm{Mn}$ clusters with $\mathrm{Mn}$-Mn distances between about 2.4 and $3.7 \AA$. At $523 \mathrm{~K}$, the Fourier transform presents a $\mathrm{Mn}-\mathrm{O}$ bond as a first shell $(\mathrm{N}=3.4$ atoms, and $\mathrm{R}=2.21 \AA)$ and $\mathrm{Mn}-\mathrm{Si}$ as an outer shell $(\mathrm{N}=4.7$ atoms, and $\mathrm{R}=3.37 \AA$ ).

EXAFS: Sn-absorption edge. Fit results of the data of the intrazeolite precursor at $298 \mathrm{~K}$, stripped of the $\mathrm{Sn}-\mathrm{Si}$ shell show 2.4 atoms of $\mathrm{C}$ or $\mathrm{O}$ at $2.13 \AA$ and the $\mathrm{Sn}-\mathrm{Mn}$ bond at $2.56 \AA(\mathrm{N}=1.2$ atoms). The $\mathrm{Sn}-\mathrm{Mn}$ bond length shrinks significantly compared to the $\mathrm{Sn}-\mathrm{Mn}$ bond of the precursor. This effect was also found for the $\mathrm{Sn}$-Mn bond (average distance $=2.59 \AA$ ) in $\mathrm{Cl}_{3} \mathrm{SnMn}(\mathrm{CO}){ }_{5}{ }^{79}$. Most likely, the replacement of methyl groups by electronegative ligands increases electron density for the $\mathrm{Sn}-\mathrm{Mn} \pi$ interaction by decreasing $\pi$ back-bonding in the $\mathrm{Mn}-\mathrm{C}$ bonds. This is also supported by the elongated Mn-CO distance in this sample (1.83 $\AA$ in NaY versus 1.87 $\AA$ in the acidic $\mathrm{Y}$ at RT).

From combined EXAFS, FTIR, TPD-MS and separate MS results of $\mathrm{Me}_{3} \mathrm{SnMn}(\mathrm{CO})_{5}$ in acidic Y zeolite, conclusions can be drawn as shown in Figure 5. Already at room temperature, the compound attaches to the zeolite framework at the oxygen rings of the supercage. The attachment of the molecule occurs through the $\mathrm{Sn}$ moiety by loss of $\mathrm{CH}_{4}$ gas while the $\mathrm{Sn}-\mathrm{Mn}$ bond and the $\mathrm{CO}$ ligand sphere are still intact. The substitution of methyl ligands by the oxygen atoms of the zeolite framework is supported by the EXAFS results which indicate that the electronegative oxygen atoms increase the Sn-Mn bond strength of the attached precursor in acidic Y zeolite. The resulting weakened $\mathrm{Mn}-\mathrm{CO}$ interaction is confirmed by the higher $\mathrm{CO}$ stretching frequencies of the precursor in acidic Y. Based on IR data, both mono- and di-substitution of methyl groups by the framework oxygen atoms occurs. The monosubstituted species, $(\mathrm{Oz}) \mathrm{Me}_{2} \mathrm{SnMn}(\mathrm{CO})_{5}$, is the major product at room temperature while the di-substituted species, $(\mathrm{Oz})_{2} \mathrm{MeSnMn}(\mathrm{CO})_{5}$, is formed at higher temperature, ca. $373 \mathrm{~K}$. The attached species decompose at $423 \mathrm{~K}$ by loss of $\mathrm{CO}$ ligands and cleavage of the Sn-Mn bond. One methyl ligand remains on the zeolite-attached tin atom. Unidentified $\mathrm{Mn}$ species are left inside the zeolite cavities as a result of the decomposition.

These results show that the heterobimetallic compound $\mathrm{Me}_{3} \mathrm{SnMn}(\mathrm{CO})_{5}$ can be anchored into the cages of acidic zeolites at room temperature under retention of the Sn$\mathrm{Mn}$ bond. The methyl ligands are good leaving groups in acidic $\mathrm{Y}$ but do not react in 


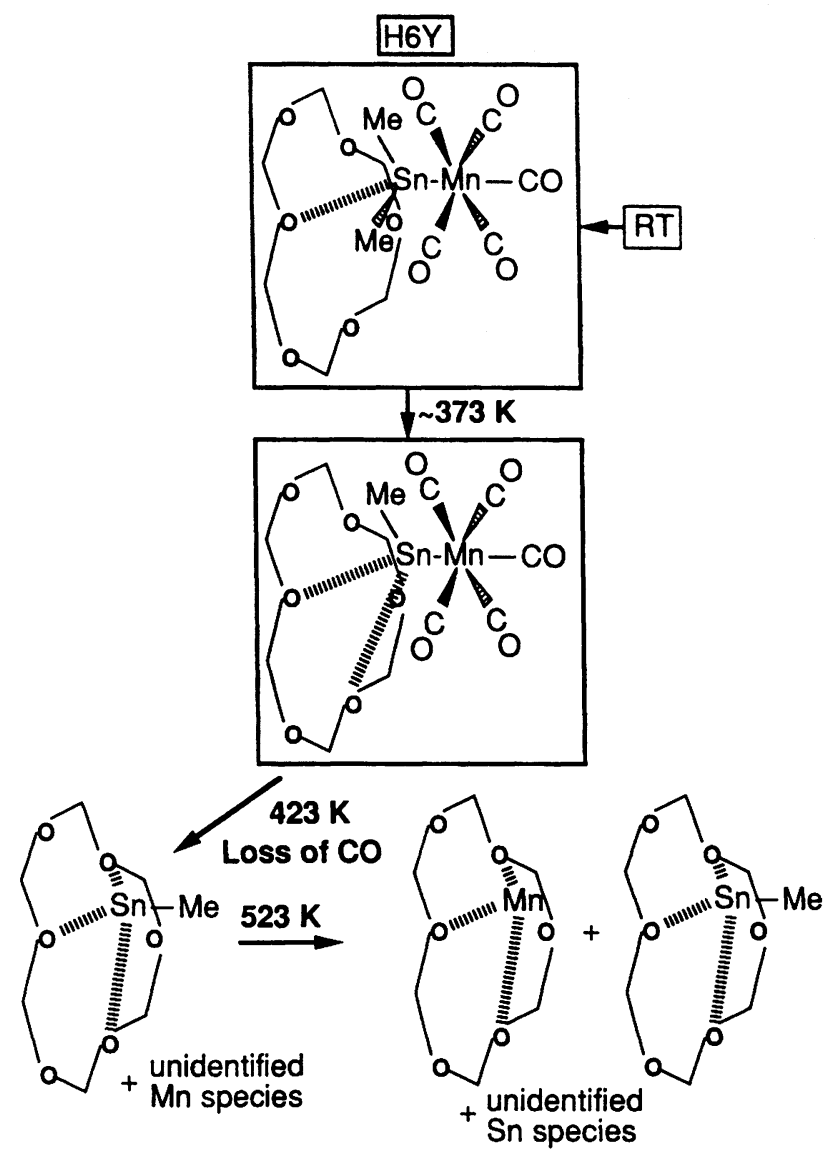

Figure 5. The chemistry of $\mathrm{Me}_{3} \mathrm{SnMn}(\mathrm{CO})_{5}$ in acid $\mathrm{Y}$ zeolite. 
$\mathrm{NaY}$. The thermal stability of the intrazeolite, attached species permits further studies on their chemical reactivity and potential catalytic activity.

\section{Polyacrylonitrile Chains in Zeolite Channels: Polymerization and} Pyrolysis. The quest for ever smaller and faster devices for information processing aims at the control of electronic conductivity at nanometer dimensions. Conducting organic polymers are interesting candidates for this purpose. Studies of the conduction mechanism of conjugated polymers ${ }^{80,81,82,83,84}$ would benefit substantially if the lowdimensional structures were available as decoupled, structurally well-defined entities. We have recently demonstrated the encapsulation of conjugated polymers such as polypyrrole, polyaniline and polythiophene in zeolite channels. ${ }^{85}$ Precursor monomers are introduced into the zeolite host and are subsequently polymerized by appropriate oxidants in the pore system. Methylacetylene gas reacts with the acid sites in zeolites L, Y, and others to form reactive, conjugated oligomers. ${ }^{86}$ Short-chain oligomers of polythiophene were prepared, oxidatively doped to the conducting state and stabilized in Na-pentasil zeolites 87 . The synthesis of these and related systems is a step towards the design of oriented "molecular wires", that could in principle permit to process signals or to store information inside channel systems with nanometer dimensions.

As a last example of zeolite inclusion chemistry, we discuss the assembly of polyacrylonitrile (PAN) strands in different large-pore zeolites, zeolite $Y$ and mordenite, and explore the pyrolysis reactions of the encapsulated polymer (Figure 6). 88

Acrylonitrile vapor was adsorbed in the degassed $\left(670 \mathrm{~K}, 10^{-5} \mathrm{Torr}\right)$ zeolite crystals at a vacuum line for $60 \mathrm{~min}$ at $298 \mathrm{~K}$. To an aqueous suspension of the acrylonitrile-containing zeolite were added aqueous solutions of potassium peroxodisulfate and sodium bisulfite as radical polymerization initiators. ${ }^{89}$ The zeolite frameworks could be dissolved with HF to recover the intrazeolite polyacrylonitrile (PAN). IR and NMR data show no damage to the polymers after this treatment. For pyrolysis, the zeolite/PAN adducts were heated under nitrogen or vacuum to 920 and $970 \mathrm{~K}$ for extended periods.

On saturation, zeolite $Y$ contains 46 and mordenite 6 molecules of acrylonitrile per unit cell. The polymer recovered from the zeolite hosts is identical to bulk PAN as shown by NMR spectroscopy. 90 The ${ }^{1} \mathrm{H}$ NMR spectra show two bands at a ratio of 2 to 1 , one at $2.0 \mathrm{ppm}$ corresponding to the methylenic group in the polymer, and the other at $3.1 \mathrm{ppm}$ confirming a methine group. The ${ }^{13} \mathrm{C}$ NMR data of the zeoliteextracted PAN show $\mathrm{CH}_{2}(27.5 \mathrm{ppm}), \mathrm{CH}$ (32.7 ppm ), and $-\mathrm{CN}$ (120.1 ppm), idertical to the bulk material.

Infrared spectra of the zeolite/polymer inclusions and of PAN extracted from the zeolites show also peaks characteristic of the bulk polymer, 91,92 including methylenic C-H stretching vibrations of the backbone $\left(2940 \mathrm{~cm}^{-1}\right.$ and at $\left.2869 \mathrm{~cm}^{-1}\right)$, and a band at $224) \mathrm{cm}^{-1}$ due to the pendant nitrile group. The spectra of the extracted intrazeolite polymers are indistinguishable from the spectrum of the bulk polymer. We conclude that the polymer formed in the zeolites is polyacrylonitrile.

Gel permeation chromatography was used to determine the molecular weight of the polymer extracted from the zeolites, relative to a PAN broad standard $\left(\mathrm{M}_{\mathrm{w}}=\right.$ $86,\left(00 ; M_{n}=23,000\right)$. For PAN extracted from $\mathrm{NaY}$, the main molecular weight distribution peaks at 19,000 , corresponding to 360 monomer units or about $0.2 \mu \mathrm{m}$ for an extended chain. For PAN extracted from $\mathrm{Na}$-mordenite, a bimodal molecular weight distibution is observed; a small fraction peaks at 19,000 and a large fraction at about $1,0 \mathrm{C} 0$, corresponsing to a $0.01 \mu \mathrm{m}$ chain in a fully extended form. The shorter chain length in mordenite might indicate crystal defects or diffusional constraints for the polymerization reaction. 
1. Adsorption of $\mathrm{CH}_{2}=\mathrm{CHCN}$ in dry zeolite $Y$

2. Intrazeolite radical polymerization
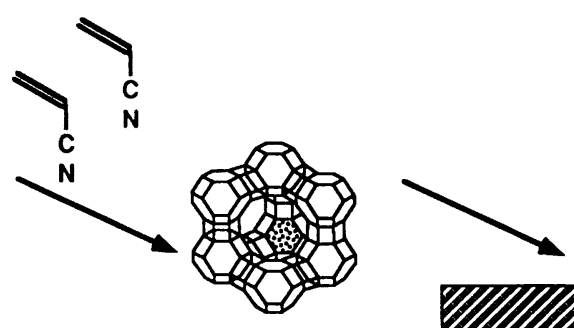
$12 \mathrm{~h}$, vacuum:

o zeolite intact

o no external polymer
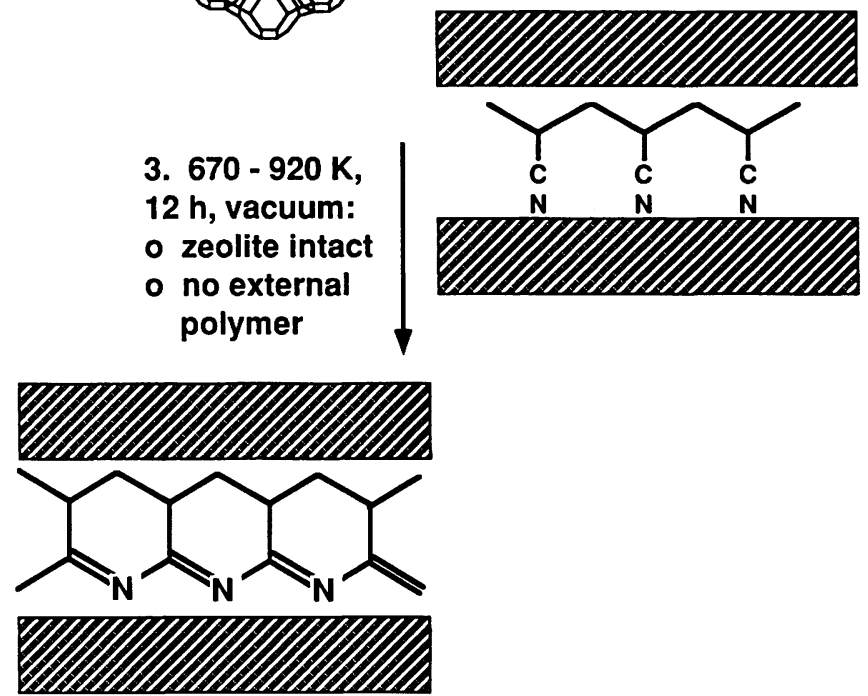

Figure 6. Intrazeolite polymerization and tentative pyrolysis product of acrylonitrile. 
Pyrolysis changes the color of the PAN-containing zeolites from white to greyblack. 93 The electronic absorption spectrum of pyrolyzed PAN extracted from $\mathrm{NaY}$ shows the appearance of a feature at about $350 \mathrm{~nm}$, as in the bulk, probably due to conjugated carbon-nitrogen double bonds in the ladder polymer. ${ }^{94}$ The rest of the spectrum is practically structureless and resembles the absorption spectrum of graphite. The methylenic stretching vibrations and the nitrile band of the intrazeolite PAN main chain disappear. New bands appear in the $1400-1600 \mathrm{~cm}^{-1}$ region which have been assigned to $\mathrm{C}=\mathrm{C}$ and $\mathrm{C}=\mathrm{N}$ double bonds in the pyrolyzed bulk PAN, as well as the tail of the electronic excitation corresponding to free carrier absorption. A sample of bulk PAN heated to $800 \mathrm{~K}$ instead of $920 \mathrm{~K}$ shows more defined features in the 1400-1600 $\mathrm{cm}^{-1}$ region, similar to the case of pyrolyzed PAN $(920 \mathrm{~K})$ extracted from the zeolite. This suggests an early stage of graphitization for the intrazeolitic material. Zeolite/PAN samples pyrolyzed at different temperatures, times, and atmospheres, (nitrogen or vacuum) show spectra similar to the spectrum of bulk PAN pyrolyzed to $800 \mathrm{~K}$.

Samples of $\mathrm{NaY}$ with pyrolyzed $(920 \mathrm{~K})$ PAN show no measurable dc conductivity. This is not surprising because the polymer is encapsulated completely within the insulating zeolite, and because no external polymer coats the zeolite crystal surfaces. However, the conductivity of the pyrolyzed PAN extracted from the zeolite is at the order of $10^{-5} \mathrm{Scm}^{-1}$, almost identical with that of bulk PAN pyrolyzed at $800 \mathrm{~K}$, and five orders of magnitude smaller than that of the bulk sample pyrolyzed at $920 \mathrm{~K}$. In contrast to the bulk polymer, pyrolysis treatment conditions above about $870 \mathrm{~K}$ have little effect on the resulting conductivity of the extracted intrazeolite samples. We conclude that the spatial limitations within the zeolite channels prevent the formation of more extended, graphitized structures with higher conductivity.

This study demonstrates the inclusion synthesis of polyacrylonitrile in the channel systems of $\mathrm{NaY}$ and $\mathrm{Na}$-mordenite zeolites, and its pyrolysis to yield a conducting material consisting of nanometer size carbon filaments. These and related systems are promising candidates for low-field conductivity at nanometer scale dimensions.

Conclusion. The examples discussed above demonstrate the versatility and great potential of zeolite molecular sieves to encapsulate and stabilize often unusual forms of matter. The zeolite pores form nanometer size reaction chambers that permit ready access to the external world via adsorption and ion exchange. The regular arrangement of the cages and their variable connectivity is of great interest for superlattice assembly of electronic and optical materials.

So far, research in this area has emphasized metal clusters, organometallics, and quantum size semiconductor clusters and superlattices. As experimental techniques become available, the dynamics of intrazeolite reactions, such as catalysis, ligand exchange, 95 electron transfer and radical reactions, and polymerizations will be explored in more detail. As molecular sieves with ever larger pores are being discovered, the future potential to assemble and understand supramolecular structures is enormous.

Acknowledgments. The author wishes to thank the students in our group who have worked on the above projects for their important contributions ( $A$. Borvornwattananont and P. Enzel). The fruitful collaboration with our coauthors is also gratefully acknowledged (M. M. Eddy, N. Herron, D. C. Koningsberger, K. Moller, and G. D. Stucky). We appreciate funding from the Sandia University Research Program (DOE), the U. S. Department of Energy (DE-FG04-90ER14158), Sprague Electric Company, and ONR (G. D. S.). Acknowledgment is also made to the Donors of the Petroleum Research Fund, administered by the American Chemical 
Society, for partial funding of this research. The operational funds for NSLS beamline X11A are supported by DOE grant \# DE-ASO580ER 10742.

\section{Literature cited}

1 Breck, D.W. "Zeolite Molecular Sieves", R.E. Krieger Publishing Co., Malabar, FL, 1984

2 "New Developments in Zeolite Science and Technology", Murakami, Y; lijima, A; Ward, J.W., eds., Kodansha, Tokyo, 1986

3 R. Szostak, Molecular Sieves. Principles of Synthesis and Identification, Van Nostrand Reinhold, New York, 1989.

4 Haushalter, R. C.; Strohmaier, K. G.; Lai, F. W. Science 1989, 246, 1289

5 Bedard, R. L.; Wilson, St. T.; Vail, L. D.; Bennett, J. M.; Flanigen, E. M. Studies Surf. Science Catal. 49, Elsevier,1989, 375

6 Meier, W.M. "New Developments in Zeolite Science and Technology", Murakami, Y; Iijima, A; Ward, J.W., eds., Kodansha, Tokyo, 1986, 13

7 Atlas of Zeolite Structure Types. Meier, W. M.; Olson, D. H. 2nd Ed., Butterworths, London, 1987

8 (a) Barrer, R. M. "Hydrothermal Synthesis of Zeolites", Academic Press, London, 1982. (b) Szostak, R. "Molecular Sieves. Principles of Synthesis and Identification", Van Nostrand Reinhold, 1989

9 B. M. Lok, T. R. Cannan, and C. A. Messina, Zeolites, 1984, 4, 289.

10 R. J. Argauer, and G. R. Landolt, US Patent 3,702,886, 1972.

11 P. A. Jacobs, Carboniogenic Activity of Zeolites, Elsevier, Amsterdam, 1977.

12 J. W. Ward, J. Catal., 1968, 11, 238.

13 Ball, W.J.; Dwyer, J.; Garforth, A.A.; Smith, W.J. "New Developments in Zeolite Science and Technology", Murakami, Y; Iijima, A; Ward, J.W., eds., Kodansha, Tokyo, 1986, 137

14 Messina, C.A.; Lok, B.M.; Flanigen, E.M. U. S. Patent 4,544,143

15 S. T. Wilson, B. M. Lok, C. A. Messina, T. R. Cannan, and E. M. Flanigen, J. Am. Chem. Soc., 1982, 104, 1146.

16 M. E. Davis, C. Saldarriaga, C. Montes, J. Garces, and C. Crowder, Zeolites, $1988,8,362$.

17 B. M. Lok, C. A. Messina, R. L. Patton, R. T. Gajek, T. R. Cannan, and E. M. Flanigen, J. Am. Chem. Soc., 1984, 106, 6092.

18 Chemical \& Engineering News, Sept. 30, 1991, 31

19 Kessler, H. Mat. Res. Soc. Symp. Proc. Vol. 233, 1991, 47

20 (a) Ozin, G. A.; Kuperman, A.; Stein, A. Angew. Chem. Int. Ed. Engl., 1989, 28, 359. (b) Ozin, G. A.; Gil, C. Chem. Rev. 1989, 89, 1749.

21 Sachtler, W. H. M., Stud. Surf. Sci. Catal. 49, Elsevier, 1989, 975

22 Barrer, R. M. "Hydrothermal Synthesis of Zeolites", Academic Press, London, 1982, 306

23 "Contribution of Clusters Physics to Materials Science and Technology", Ed.

Davenas, J., Rabette, P. M. ; NATO ASI Series, E104 ; Martinus Nijhoff:

Dordrecht, 1986

24 "Metal Clusters", Ed. M. Moskovits; Wiley: New York, 1986

25 Van Hardeveld, R.; Hartog, F. Surf. Sci. 1969, 15, 189

26 Somorjai, G. A., in "Catalyst Design", Hegedus, L. L., Ed.; Wiley: New York, 1987, 11

27 Exner,D.; Jaeger, N.; Moller, K.; Schulz-Ekloff, G. J. Chem. Soc., Faraday Trans. 1, 1982, 78, 3537 
Exner, D.; Jaeger, N.; Moller, K.; Nowak, R.; Schrubbers, H.; Schulz-Ekloff, G.; Ryder, P. Studies in Surf. Sci, Vol. 12, Ed. Jacobs, P.A.; Elsevier:Amsterdam, 1982, 205

29 Bergeret, G.; Gallezot, P.; Imelik, B. J. Phys. Chem. 1981, 85, 411 Gallezot, P.; Imelik, B. Adv. Chem. Ser. 1973, 121, 66

Bergeret. G.; Tran Manh Tri; Gallezot, P. J. Phys. Chem. 1983, 87, 1160

Moller, K.; Koningsberger, D. C.; Bein, T. J. Phys. Chem., 1989, 93, 6116 Teo, B. K. "EXAFS: Basic Principles and Data Analysis"; Springer: Berlin, 1986

"X-Ray Absorption: Principles, Applications, Techniques of EXAFS,

SEXAFS and XANES", Koningsberger, D. C.; Prins, R., Ed.; Wiley: New York, 1987

Costenoble, M. L.; Mortier, W. J.; Uytterhoeven, J. B. J. Chem. Soc.,

Faraday Trans. 1 1978, 74, 466 Calligaris, M.; Nardin, G.; Randaccio, L.; Zangrando, E. Zeolites 1986, 6, 439

38 Nedeljkovic, J. M.; Nenadovic, M. T.; Micic, O. I.; Nozik, A. J. J. Phys. Chem. 1986, 90, 12

Nozik, A. J.; Williams, F.; Nenadovic, M. T.; Rahj, T.; Micic, O. I. J. Phys. Chem. 1985, 89, 397

40 Henglein, A. Ber. Bunsen Ges. Phys. Chem. 1984, 88, 969

41 Ramsden, J. J.; Webber, S. E.; Grätzel, M. J. Phys. Chem. 1985, 98, 2740

42 Dannhauser, T.; O'Neil, M.; Johansson, K.; Whitten, D.; McLendon, G. J.

Phys. Chem. 1986, 90, 6074

43 Tricot, Y.-M.; Fendler, J. H. J. Phys. Chem. 1986, 90, 3369

44 Variano, B. F.;Hwang, D. M.; Sandroff, C. J.; Wiltzius, P.; Jing, T. W.; Ong, N. P. J. Phys. Chem. 1987, 91, 6455

45 Ekimov, A. I.;Efros, Al. L.; Onushchenko, A. A. Solid State Comm. 1985, 921

46 Wang, Y.; Mahler, W. Opt. Comm. 1987, 61, 233

47 Chestnoy, N.; Hull, R.; Brus, L. E. J. Chem. Phys. 1986, 85, 2237

48 Stucky, G. D.; Mac Dougall, J. E. Science, 1990, 247, 669

49 Parise, J. B.; MacDougall, J. E.; Herron, N.; Farlee, R.; Sleight, A. W.;

Wang, Y.; Bein, T.; Moller, K.; Moroney, L. M. Inorg. Chem. 1988, 27, 221

50 Herron, N.; Wang, Y.; Eddy, M.; Stucky, G. D.; Cox, D. E.; Moller, K.;

Bein, T.; J. Am. Chem. Soc., 1989, 111, 530

51 Moller, K.; Eddy, M. M.; Stucky, G. D.; Herron, N.; Bein, T. J. Am. Chem.

Soc., 1989, 111, 2564

52 Bard, A. J. J. Phys. Chem 1982, 86,172

53 Grätzel, M. Acc. Chem. Res. 1982, 15, 376

54 Darwent, J. R. J. Chem. Soc., Faraday Trans. 1 1984, 80, 183

55 Lamb, H. H.; Gates, B. C.; Knözinger, H. Angew. Chem. Int. Ed.

Engl. 1988, 27, 1127

56 Basset, J.M.; Choplin, A J. Mol. Catal. 1983, 21, 95

57 Bailey, D.C.; Langer, S.H. Chem. Rev. 1981, 81, 109

58 Jardin, F.H. Prog. Inorg. Chem. 1981, 28, 63

59 Ballivet-Tkatchenko, D.; Coudurier, G.; Mozzanega, H.;

Tkatchenko, I.; Kinnemann, A. J. Mol. Catal. 1979, 6, 293

60 Suib, S.L.; Kostapapas, A.; McMahon, K.C.; Baxter, J.C.; Winiecki, A.M. Inorg. Chem. 1985, 24, 858 
61 Bein, T.; McLain, S.J.; Corbin, D.R.; Farlee, R.F.; Moller, K.;

Stucky, G.D.; Woolery, G.; Sayers, D. J. Am. Chem. Soc. 1988, 110,1801

62 Bein, T.; Schmiester, G.; Jacobs, P.A. J. Phys. Chem. 1986, 90, 4851

63 Yang, Y.S.; Howe, R.F. "New Developments in Zeolite Science and Technology", Murakami, Y.; Iijima, A.; Ward, J.W., eds., Kodansha, Tokyo, 1986,883

64 Herron, N. Inorg. Chem. 1986, 25, 4714

65 Diegruber, H.; Plath, P.J.; Schulz-Ekloff, G. J. Mol. Catal. 1984, 24,115

66 Herron, N.; Stucky, G.D.; Tolman, C.A. J.C.S., Chem. Comm. 1986,521

67 Verdonck, J.J.; Schoonheydt, R.A.; Jacobs, P.A. J. Phys. Chem. $1983,87,683$

68 Gelin, P.; Naccache, C.; Ben Taarit, Y.; Diab, Y. Nouv. J. Chim. $1984,8,675$

69 Bergeret, G.; Gallezot, P.; Gelin, P.; Ben Taarit, Y.; Lefebvre, F.;

Naccache, C.; Shannon, R.D. J. Catal. 1987, 104, 279

70 Davis, M.E.; Schnitzer, J.; Rossin, J.A.; Taylor, D.; Hanson, B.E. J. Mol. Catal. 1987, 39, 243

71 Shannon, R.D.; Vedrine, J.C.; Naccache, C.; Lefebvre, F. J. Catal. $1984,88,431$

72 Rode, E.J.; Davis, M.E.; Hanson, B.E. J. Catal. 1985, 96, 574

73 Huang, T.N.; Schwartz, J.; Kitajima, N. J. Mol. Catal. 1984, 22, 38

74 Huang, T.N.; Schwartz, J. J. Am. Chem. Soc. 1982, 104, 5244

75 Corbin, D.R.; Seidel, W.C., Abrams, L.; Herron, N.; Stucky, G.D.; Tolman, C.A. Inorg. Chem. 1985, 24, 1800

76 Taylor, D. F.; Hanson, B. E.; Davis, M. E. Inorg. Chim. Acta 1987, 128,55

77 (a) Borvornwattananont, A.; Moller, K.; Bein, T. J. Chem. Soc., Chem. Commun. 1990, 28. (b) Borvornwattananont, A.; Moller, K.;

Bein, T., Synthesis/Characterization and Novel Applications of Molecular Sieve Materials, R. L. Bedard, T. Bein, M. E. Davis, J. Garces, V. A. Maroni, G.

D. Stucky, Eds., Mat. Res. Soc. Symp. Proc. 233, 1991, p. 195.

(c) Borvornwattananont, A.; Bein, T., submitted.

Borvornwattananont, A.; Bein, T., submitted.

79 Onaka, S., Bull. Chem. Soc. Japan, 1975, 48(1), 319.

80 Proceedings of the International Conference on Science and Technology of Synthetic Metals, ICSM '88 and '90; Synth. Metals 1988, 28 (1-3) and 29(1), and Synth. Metals 1991, 41-43.

81 Handbook of Conducting Polymers; T. A. Skotheim, Ed.; Marcel Dekker, New York, Vol. 1, 1986.

82 Conducting Polymers. Special Applications; L. Alcacer, Ed.; D. Reidel, Dordrecht, 1987.

83 Hopfield, J. J.; Onuchic, J. N.; Beratan, B. N. Science 1988, 241, 817

84 (a) Molecular Electronic Devices; F. L. Carter, Ed., Marcel Dekker, New York, 1982.

(b) Molecular Electronic Devices II; F. L. Carter, Ed., Marcel Dekker, New York, 1987.

(a) Enzel, P.; Bein, T. J. Phys. Chem. 1989, 93 , 6270. 
(b) Enzel, P.; Bein, T. J. Chem. Soc., Chem. Commun. 1989, 1326.

(c) Bein, T.; Enzel, P. Angew. Chem., Int. Ed. Engl. 1989, 28, 1692.

(d) Bein, T.; Enzel, P. Mol. Cryst. Liq. Cryst., 1990, 181, 315.

(e) Bein, T.; Enzel, P. ; Beuneu, F.; Zuppiroli, L.

"Inorganic Compounds with Unusual Properties III. Electron Transfer in Biology and the Solid State", M. K. Johnson et al., Eds., ACS Adv.

Chem. Ser., No. 226, 1990, p. 433

86 Cox, S. D.; Stucky, G. D. J. Phys. Chem., 1991, 95, 710.

87 Caspar, J. V.; Ramamurthy, V.; Corbin, D. R. J. Am. Chem. Soc., 1991, 113, 600.

88 Enzel, P.; Bein, T., submitted.

89 At molar ratios acrylonitrile: peroxodisulfate: bisulfite of 1:0.0027:0.0035.

90 G. Svegliado, G. Talamini, and G. J. Vidotto, Polym. Sci. A-1, 1967, 5, 2875.

91 M. M. Coleman, and R. J. Petcavich, J. Polym. Sci. Phys. Ed., 1978, 16, 821.

92 T. -C. Chung, Y. Schlesinger, S. Etemad, A. G. MacDiarmid, and A. J. Heeger, J. Polym. Sci. Phys. Ed., 1984, 22, 1239.

93 X-ray powder diffraction data demonstrate that the zeolite framework remains intact even after pyrolysis treatments at $970 \mathrm{~K}$ for $\mathrm{NaY}$. Scanning electron micrographs show no apparent external bulk polymer coating the zeolite crystals indicating that most of the polymer chains reside in the interior of the zeolite crystals.

94 C. L. Renschler, A. P. Sylwester, and L. V. Salgado, J. Mat. Res. 1989, 4, 452.

95 Ozin, G. A.; Özkar, S.; Pastore, H. O.; Poë, A. J.; Vichi, E. J. S. J. Chem. Soc., Chem. Commun., 1991, 141.

RECEIVED April 7, 1992 